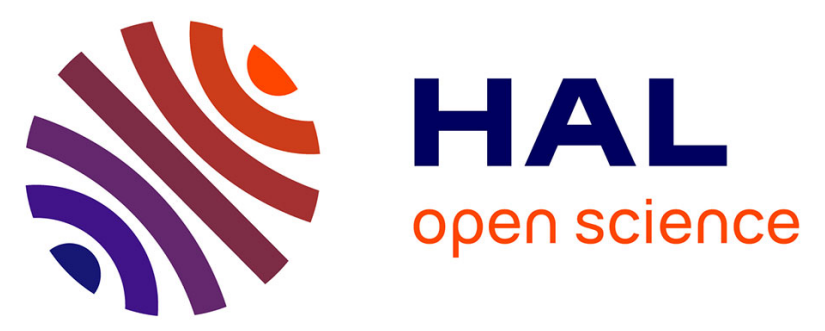

\title{
An intuitionistic fuzzy grey model for selection problems with an application to the inspection planning in manufacturing firms
}

\author{
Seyed Meysam Mousavi, Shirin Mirdamadi, Ali Siadat, Jean-Yves Dantan, \\ Reza Tavakkoli-Moghaddam
}

\section{To cite this version:}

Seyed Meysam Mousavi, Shirin Mirdamadi, Ali Siadat, Jean-Yves Dantan, Reza TavakkoliMoghaddam. An intuitionistic fuzzy grey model for selection problems with an application to the inspection planning in manufacturing firms. Engineering Applications of Artificial Intelligence, 2015, 39, pp.157-167. 10.1016/j.engappai.2014.12.004 . hal-02519423

\section{HAL Id: hal-02519423 \\ https://hal.science/hal-02519423}

Submitted on 26 Mar 2020

HAL is a multi-disciplinary open access archive for the deposit and dissemination of scientific research documents, whether they are published or not. The documents may come from teaching and research institutions in France or abroad, or from public or private research centers.
L'archive ouverte pluridisciplinaire HAL, est destinée au dépôt et à la diffusion de documents scientifiques de niveau recherche, publiés ou non, émanant des établissements d'enseignement et de recherche français ou étrangers, des laboratoires publics ou privés. 


\title{
An intuitionistic fuzzy grey model for selection problems with an application to the inspection planning in manufacturing firms
}

\author{
S.M. Mousavi ${ }^{\mathrm{a}, \mathrm{b}, *}$, S. Mirdamadi ${ }^{\text {b }}$, A. Siadat ${ }^{\mathrm{b}}$, J. Dantan ${ }^{\text {b }}$, R. Tavakkoli-Moghaddam ${ }^{\mathrm{c}, \mathrm{d}}$ \\ a Industrial Engineering Department, Faculty of Engineering, Shahed University, Tehran, Iran \\ ${ }^{\mathrm{b}}$ LCFC, Arts et Métier Paris Tech, Centre de Metz, Metz, France \\ c School of Industrial Engineering and Engineering Optimization Research Group, College of Engineering, University of Tehran, Tehran, Iran \\ ${ }^{\mathrm{d}}$ Research Center for Organizational Processes Improvement, Sari, Iran
}

\begin{abstract}
Most of complex selection problems in real-life applications are considered under multiple conflicting attributes for manufacturing firms. The appropriate selection plays an important role in the firm's performance from the tactical and operational viewpoints. The classical methods for the selection problems in manufacturing firms are inadequate to deal with uncertainties, including insufficiency in information availability and the imprecise or vague nature in experts' judgments and preferences. To overcome these difficulties, this paper introduces a novel distance-based decision model for the multiattributes analysis by considering the concepts of intuitionistic fuzzy sets (IFSs), grey relations and compromise ratio approaches. A weighting method for the attributes is first developed based on a generalized version of the entropy and IFSs along with experts' judgments. Then, a new grey relational analysis is introduced to analyze the extent of connections between two potential scenarios by an intuitionistic fuzzy distance measurement. Finally, a new intuitionistic fuzzy compromise ratio index to prioritize the scenarios is proposed by considering the weight of the strategy for the maximum group utility in intuitionistic fuzzy grey environment. The feasibility and practicability of the proposed distance-based decision model is illustrated in detail, and it is implemented in a real case study to the inspection planning for the oil pump housing from Renault automobile manufacturing.
\end{abstract}

\section{Introduction}

Multi-attributes decision making (MADM) is the process of finding the most suitable alternative or candidate from all of the feasible alternatives for evaluation and selection problems. The increasing complexity of the manufacturing environment makes it less possible for decision makers (DMs) or experts to take into account all relevant properties of the evaluation and selection problem (Mojtahedi et al., 2010; Mousavi et al. 2013a,c), and then to provide performance ratings of each alternative and the relative importance of each attribute by precise values. In fact, much knowledge presented by the DMs or experts would be imprecise or incomplete judgments rather than exact and numerical values; As a result, uncertain situations should be considered for MADM methods in real-life applications. The MADM methods under uncertainty have been widely spread in real-world decision situations in the manufacturing environment; for instance, selection of e-sourcing (Singh and Benyoucef, 2011), evaluation of flexible manufacturing systems (Vahdani et al., 2013b) and new product selection (Mousavi et al., 2013b).

Regarding the recent application of MADM methods in real-life complex decision problems, for instance, Mojtahedi et al. (2010) applied group decision-making approach based on the technique for order preference by similarity to ideal solution (TOPSIS) for concurrently identifying and evaluating risks in gas refinery plants. Singh and Benyoucef (2011) proposed a fuzzy TOPSIS based methodology to solve the sealed-bid, multi-factors reverse auction problem of esourcing. Vahdani et al. (2011) developed fuzzy multi-criteria analysis for ranking and selecting the potential alternatives based on the fuzzy modified TOPSIS method. Then, the presented method was applied to the rapid prototyping process selection and the robot selection problems. Hamzacebi and Pekkaya (2011) used the grey relational analysis (GRA) to determine stock investments and three different methods, including heuristic, analytic hierarchy process (AHP), and learning via sample, were considered to obtain the attributes' weights. Ebrahimnejad et al. (2012) hybridized a modified analytic network process (ANP) and an improved VIKOR (VlseKriterijumska Optimizacija I Kompromisno Resenje in Serbian, it means multi-criteria optimization and compromise) for construction 
project selection in the fuzzy environment. Vahdani et al. (2013a) introduced the compromise solution method for solving fuzzy group decision-making problems by considering both conflicting evaluation criteria. The proposed method is then applied to a case study for the contractor selection problem in construction industry.

In the manufacturing environment, numerous companies are brought to be more and more attentive to the process variations, resulting in product's dimensional and geometrical specification variations. Facing production variations and tight geometrical tolerances, modern manufacturing intends as well to ensure the product functionalities and requirements through adequate solutions. These two go through an effective inspection plan with certain particularity as major functions to satisfy the global criteria (attributes) common on all design stages. Hence, the performance despite conflicting industrial objectives of a production system has become to take global, not local, proportions so that the inspection planning is regarded as an integral part of the design, manufacturing process selection and process planning (Zhao et al., 2009).

Elaborating an inspection plan, experts' knowledge is integrated to decision making, and human subjectivities are attached. Sometimes they are brought to estimate risk factors while no explicit knowledge is available. The granularity of information provided by the experts determines the development of solutions. Despite quantitative and qualitative information, an inspection plan should be associated to an adequacy note, regarding to the global performance. In a decision-making context, multiple facets of performance can be translated and dispersed across multiple sub-criteria. They cause complex problems as sets of conflicting criteria are usually treated concurrently. The definition and the decomposition of the criteria (i.e., main strategic guidelines) impact on the final operational decisions regarding the relevance of inspection plan candidates. Also, this is suitable for the evaluation of criteria regarding the granularity of information.

For all the above-mentioned purposes, industries should concentrate on the inspection planning from tactical and operational point of views to meet their objectives in terms of quality, cost and time, and to respect their constraints as feasibility and competitive economic contexts. This problem can be viewed within the context of an MADM framework. Decision-making techniques can aggregate multiple criteria and their weights to one global adequacy note for each inspection scenario associated to the criteria. A significant decision for an inspection plan, including product conformity control and process monitoring, proposes a compromise solution among the non-conformity rate seen by customers, the manufacturing and inspection cost and the realization difficulty of products regarding the awaited functionalities and requirements.

Most researchers have focused on the computer-aided inspection planning; however, few studies have been conducted on the selection of the best inspection scenario in manufacturing firms. Regarding the related literature on decision-making methods in the inspection process planning, Pandey and Kengpol (1995) developed a model for selecting the best possible automated inspection device in flexible manufacturing systems. For this purpose, they employed the preference ranking organization method for enrichment evaluations (PROMETHEE) to appraise alternatives. Ferreira et al. (2009) presented a decision model with the multi-attribute utility theory to determine inspection intervals of condition monitoring based on delay time analysis. Bana e Costa et al. (2012) introduced a multi-attribute model for auditing a predictive maintenance programme (PMP) developed and implemented in the general hospital of ciudad real (GHCR) in Spain, and applied the measuring attractiveness by a categorical based evaluation technique (MACBETH) to establish a hierarchical additive value model with attributes' weights.
The review of the related literature indicates that although some researchers have studied the inspection planning from tolerance-driven and geometry-based computer-aided planning in manufacturing systems; none of them have considered the selection of inspection scenarios by the MADM methods. Moreover, multi-attributes analysis and inspection scenario selection have not been investigated in an uncertain environment.

For the first time in the literature, this paper presents a new distance-based intuitionistic fuzzy grey model to solve inspection scenario selection problems in manufacturing firms. In numerous decision problems for real-world manufacturing applications, for some of attributes while exact evaluations can be determined, for others they cannot. Experts or DMs usually need to express their preferences over alternatives versus the selected attributes. Considering the competitive market environment, the decisions become more complex. The preference information and judgments provided by the DMs may be incomplete and insufficient. They can be regarded as uncertain or hesitation issues because they have made decisions under time pressure and lack of knowledge or data in practice. In fact, since experts' opinions and preferences are often vague and complex and they cannot estimate their preferences with exact values, linguistic evaluations can only be given instead of exact evaluations. In such cases, it seems to be well suited to express the DMs' preferences in intuitionistic fuzzy sets (IFSs) with ill-known membership grades, which is a generalization of the Zadeh's fuzzy set. The IFS theory is proper and suitable for expressing hesitation of the DMs or experts for manufacturing decision problems and applications under uncertainty (Vahdani et al., 2013b). It assists the DMs to utilize more flexible ways to express real-world decision situations provided by the truthmembership function and non-truth-membership function for an element in order to indicate the degrees of satisfaction and nonsatisfaction. In recent years, the IFS has been widely employed to many decision-making problems with remarkable results (e.g., Boran et al., 2009; Jiang et al., 2011; Vahdani et al., 2013b).

Since there is a few research on fuzzy grey MADM by considering their advantages and these kinds of problem solving approaches can be more objective in expressing some decision-making situations under uncertainty in reality, the fuzzy and grey theories are worthy of more attention. Hence, this paper introduces a new decision model to meet the demands of practical decision problems in manufacturing firms. For this purpose, a new design of distancebased model is proposed in this paper to handle complex decisionmaking problems in an uncertain environment. The presented model is based on the integration of the IFS theory and the grey relational analysis (GRA) along with multi-attributes analysis. Firstly, linguistic terms characterized by intuitionistic fuzzy numbers along with numerical values are taken into account to obtain the importance of selected scenario (i.e., alternative) and to provide the performance rating of scenarios in terms of the conflicting attributes. The intuitionistic fuzzy numbers employ the truth-membership function and non-truth-membership function to point out the degrees of satisfaction and non-satisfaction of each scenario by considering a set of attributes, respectively. Secondly, a weighting method is developed based on a generalized version of the entropy and IFSs as well as experts' judgments to determine the importance of attributes. Thirdly, a new GRA is introduced to analyze the extent of connections between two potential scenarios by an intuitionistic fuzzy distance measurement, which plays an important role in the selection problem. Finally, a new intuitionistic fuzzy compromise ratio index is presented to evaluate the scenarios and to select the most suitable scenario in a complex environment.

A real case study in the automotive industry in France for the selection problem of the inspection planning is presented to demonstrate the applicability of the intuitionistic fuzzy grey distance-based model. The computational results illustrate that the proposed model is suitable and proper as the decision-making approach to analyze 
the inspection scenarios in an uncertain environment in the manufacturing firms.

In sum, the main contributions of this paper are provided as follows:

- Presenting a new intuitionsitic fuzzy version of distancebased methods by utilizing linguistic terms and numerical values, in which performance ratings of potential scenarios in terms of a set of selected subjective and objective attributes, and the importance of each attribute given by considering their truth membership and non-truth-membership functions.

- Developing a new intuitionsitic fuzzy GRA by considering the correlations between the reference level scenarios and other compared scenarios in a complex and uncertain environment.

- Proposing a new intuitionistic fuzzy compromise ratio index to assess and select the scenarios by considering the weight of the strategy for the maximum group utility in a complex and uncertain environment.

The rest of this paper is organized as follows. In Section 2, basic concepts and definitions of IFSs and GRA are reviewed. In Section 3, the proposed new distance-based intuitionistic fuzzy grey model is introduced based on combining the concepts of IFSs and GRA. In Section 4, a case study by applying the proposed model to evaluate the inspection scenarios in the automotive industry is presented, after which this paper describes how the new intuitionistic fuzzy grey decision model is effective. Finally, conclusions are provided in Section 5.

\section{Review of the basic concepts and definitions}

In this section, basic concepts and definitions of the IFSs theory as well as the GRA employed in this paper are briefly provided as below.

\subsection{Intuitionistic fuzzy sets (IFSs)}

The concept of IFS was originally introduced by Atanassov (1986) which has been characterized by three main degrees, including membership degree, non-membership degree and hesitancy degree. The IFS is more flexible and suitable to handle fuzziness and uncertainty for complex decision problems (Atanassov, 1999) than the traditional fuzzy sets introduced by Zadeh (1965). Some definitions of the IFSs are presented as follows:

Definition 2.1.1. An IFS $A$ on the universe of discourse $U$ is defined as an object of the form (Atanassov, 1986):

$A=\left\{\left\langle x, \mu_{A}(x), \nu_{A}(x)\right\rangle \mid x \in U\right\}$.

In this expression, the maps $\mu_{A}: U \rightarrow[0,1]$ and $\nu_{A}: U \rightarrow[0,1]$ represent the membership and non-membership degree functions of $A, \mu_{A}$ and $\nu_{A}$ represent the degrees of membership and nonmembership of the element $x$ to the set $A$, respectively. The following inequalities should be satisfied by these two quantities:

$0 \leq \mu_{A}(x)+\nu_{A}(x) \leq 1$

Obviously, when the right equality holds, the IFS decreases to a traditional fuzzy set; when the left equality meets, it considers that a DM or expert is completely hesitated about the decision making (Atanassov, 1999).
Definition 2.1.2. An IFS $A$ includes a non-negative value for each $x \in U$ (Atanassov, 1986):

$\pi_{A}(x)=1-\mu_{A}(x)-\nu_{A}(x)$.

$\pi_{A}(x)$ is regarded as the degree of hesitation with the membership of element $x \in U$ to $A$. It is obviously observed that for each $x \in U$ :

$0 \leq \pi_{A}(x) \leq 1$

Definition 2.1.3. The summation and multiplication operations between two IFSs, $A$ and $B$, as follows (Atanassov, 1989):

$A+B=\left\{\left\langle x, \mu_{A}(x)+\mu_{B}(x)-\mu_{A}(x) \cdot \mu_{B}(x), \nu_{A}(x) \cdot \nu_{B}(x)\right\rangle \mid x \in U\right\} ;$

$A \cdot B=\left\{\left\langle x, \mu_{A}(x) \cdot \mu_{B}(x), \nu_{A}(x)+\nu_{B}(x)-\nu_{A}(x) \cdot \nu_{B}(x)\right\rangle \mid x \in U\right\}$.

Other operations of the IFSs are presented by De et al. (2000):

$n A=\left\{\left\langle x, 1-\left(1-\mu_{A}(x)\right)^{n},\left(\nu_{A}(x)\right)^{n}\right\rangle \mid x \in U\right\} ;$

$A^{n}=\left\{\left\langle x,\left(\mu_{A}(x)\right)^{n}, 1-\left(1-\nu_{A}(x)\right)^{n}\right\rangle \mid x \in U\right\}$.

Definition 2.1.4. Intuitionistic fuzzy weighted geometric by considering a weighting vector $\omega, I F W G_{\omega}$, is defined as (Xu and Yager, 2006):

$I F W G_{\omega}\left(A_{1}, A_{2}, \ldots, A_{n}\right)=\prod_{j=1}^{n} A_{j}^{\omega_{j}}=\left\langle\prod_{j=1}^{n}\left(\mu_{A_{j}}\right)^{\omega_{j}}, 1-\prod_{j=1}^{n}\left(1-\nu_{A_{j}}\right)^{\omega_{j}}\right\rangle$,

where $\omega=\left(\omega_{1}, \omega_{2}, \ldots, \omega_{n}\right)^{T}$ is the weight vector of $A_{j}(j=1,2, \ldots, n)$, $\omega_{j} \in[0,1]$, and $\sum_{j=1}^{n} \omega_{j}=1$.

Definition 2.1.5. Intuitionistic fuzzy weighted average by considering a weighting vector $\omega, I F W A_{\omega}$, is defined as (Xu, 2007a):

IFWA $A_{\omega}\left(A_{1}, A_{2}, \ldots, A_{n}\right)=\sum_{j=1}^{n} \omega_{j} A_{j}=\left\langle 1-\prod_{j=1}^{n}\left(1-\mu_{A_{j}}\right)^{\omega_{j}}, \prod_{j=1}^{n}\left(\nu_{A_{j}}\right)^{\omega_{j}}\right\rangle$,

where $\omega=\left(\omega_{1}, \omega_{2}, \ldots, \omega_{n}\right)^{T}$ is the weight vector of $A_{j}(j=1,2, \ldots, n)$, $\omega_{j} \in[0,1]$, and $\sum_{j=1}^{n} \omega_{j}=1$.

Definition 2.1.6. Distance between two IFSs, $A$ and $B$, is as follows (Szmidt and Kacprzyk, 2000):

$D(A, B)=$

$$
\sqrt{\frac{1}{2 n} \sum_{j=1}^{n}\left[\left(\mu_{A}\left(x_{j}\right)-\mu_{B}\left(x_{j}\right)\right)^{2}+\left(\nu_{A}\left(x_{j}\right)-\nu_{B}\left(x_{j}\right)\right)^{2}+\left(\pi_{A}\left(x_{j}\right)-\pi_{B}\left(x_{j}\right)\right)^{2}\right]},
$$

where $D(A, B)$ is the normalized Euclidean distance between $A$ and $B$; it is presented to measure the difference between two IFSs.

Definition 2.1.7. A score function $S$ is defined to measure an IF value $A$ as follows (Xu, 2007b):

$S(A)=\mu_{A}-\nu_{A}$,

Also, an accuracy function $H$ is defined to evaluate the accuracy degree of IF value Aas follows:

$H(A)=\mu_{A}+\nu_{A}$,

Let $A$ and $B$ be IF values,

if $S(A)<S(B)$, then $A$ is smaller than $B$, denoted by $A<B$.

If $S(A)=S(B)$, then

- if $H(A)=H(B)$, then $A$ and $B$ represent the same information, denoted by $A=B$;

- if $H(A)<H(B)$, then $A$ is smaller than $B$, denoted by $A<B$.

\subsection{Grey relational analysis (GRA)}

Grey theory was originally introduced by Deng (1982). This theory has been widely employed to solve the decision problems under uncertainty, particularly under the discrete data and information incompleteness (e.g., Wu, 2002; Hamzacebi and Pekkaya, 2011). The 
objective of the GRA from the grey theory is to provide a mathematical way to compute the correlation between the series that compose a set space (Deng, 1988; Deng, 1989a,b). In fact, the GRA is one of the well-known methods to evaluate different relationships among the discrete data sets and make decisions under multiple conflicting attributes. The main merits are that computations can be simple and straightforward, and results can be based upon the original data (Wu, 2002). Some definitions of the grey theory and GRA are presented as follows (Deng, 1989a,b; Chen and Tzeng, 2004):

Definition 2.2.1. Let $X$ be a decision factor set of grey relations, $x_{0} \in X$ the referential sequence, and $x_{i} \in X$ the comparative sequence with $x_{0}(k)$ and $x_{i}(k)$ representing, respectively, the numerals at point $k$ for $x_{0}$ and $x_{i}$. If $\gamma\left(x_{0}(k), x_{i}(k)\right)$ and $\gamma\left(x_{0}, x_{i}\right)$ are real numbers, and satisfy the following four grey axioms, then $\gamma\left(x_{0}(k), x_{i}(k)\right)$ is regarded as the grey relational coefficient of these factors in point $k$, and the grade of grey relation $\gamma\left(x_{0}, x_{i}\right)$ is the average value of $\gamma\left(x_{0}(k), x_{i}(k)\right)$.

a) Norm interval

$0<\gamma\left(x_{0}, x_{i}\right)$

$\leq 1, \forall k ; \gamma\left(x_{0}, x_{i}\right)=1$, iff $x_{0}=x_{i} ; \quad \gamma\left(x_{0}, x_{i}\right)=0$, iff $x_{0}=x_{i} \in \varphi$, where $\varphi$ is an empty set.

b) Duality symmetric

$$
x, y \in X \Rightarrow \gamma(x, y)=\gamma(y, x) \text {, iff } X=\{x, y\} .
$$

c) Wholeness

$$
\gamma\left(x_{i}, x_{j}\right) \stackrel{\text { often }}{\neq} \gamma\left(x_{j}, x_{i}\right), \quad \text { iff } X=\left\{x_{i} \mid i=0,1,2, \ldots, n\right\}, \mathrm{n}>2 .
$$

\section{d) Approachability}

$\gamma\left(x_{0}(k), x_{i}(k)\right)$ decreasing along with $\left|\left(x_{0}(k)-x_{i}(k)\right)\right|$ increasing

According to the above four axioms of grey relations, a mathematical equation for the grey relational coefficient is computed by:

$\gamma\left(x_{0}(k), x_{i}(k)\right)=\frac{\min _{i} \min _{k}\left|x_{0}(k)-x_{i}(k)\right|+\zeta \max _{i} \max _{k}\left|x_{0}(k)-x_{i}(k)\right|}{\left|x_{0}(k)-x_{i}(k)\right|+\zeta \max _{i} \max _{k}\left|x_{0}(k)-x_{i}(k)\right|}$,

where $\left|x_{0}(k)-x_{i}(k)\right|=\Delta_{i}(k)$, and $\zeta$ is the distinguished coefficient. It is regarded as the index for distinguish ability in the grey relational coefficient. The distinguished coefficient takes between 0 and 1, which is to extend or reduce the range of the grey relational coefficient.

Definition 2.2.2. If $\gamma\left(x_{0}, x_{i}\right)$ satisfies the four grey relation axioms, then $\gamma$ is considered the grey relational map.

Definition 2.2.3. If $\Gamma$ is the entirety of the grey relational map, $\gamma \in \Gamma$ satisfies the four axioms of grey relation, and $X$ is the factor set of grey relation, then $(X, \Gamma)$ is regarded as the grey relational space, while $\gamma$ is the specific map for $\Gamma$.

Definition 2.2.4. Let $(X, \Gamma)$ be the grey relational space, and if $\gamma\left(x_{0}, x_{j}\right) ; \gamma\left(x_{0}, x_{p}\right) ; \ldots ; \gamma\left(x_{0}, x_{q}\right)$ satisfy $\gamma\left(x_{0}, x_{j}\right)>\gamma\left(x_{0}, x_{p}\right)>\ldots$ $>\gamma\left(x_{0}, x_{q}\right)$, then the grey relational order is obtained as $x_{j} \succ x_{p} \succ \ldots \succ x_{q}$.

\section{Proposed intuitionistic fuzzy grey distance-based model}

Proposed evaluation and selection problems in real-life manufacturing applications under multiple attributes involve uncertain and imprecise information. These problems are taken into account where values of performance ratings for all scenarios versus multiple subjective attributes as well as the importance of each conflicting attribute are presented as linguistic terms, along with numerical values; then they can be convertible to intuitionistic fuzzy numbers. Assume that $A=\left(A_{1}, A_{2}, \ldots, A_{m}\right)$ is the set of potential scenarios and $C=$ $\left(C_{1}, C_{2}, \ldots, C_{n}\right)$ is the set of conflicting subjective and objective attributes employed in assessing the scenarios. The proposed intuitionistic fuzzy grey distance-based model involves the following steps:

Step 1. Intuitionistic fuzzy decision matrix is constructed. Assume that the performance rating of scenario $x_{i}(i \in M)$ in terms of subjective attribute $c_{j}(j \in N)$ is linguistic variable $\tilde{f}_{i j}$, which can be expressed in intuitionistic fuzzy number $x_{i j}=\left\langle\mu_{\mathrm{ij}}, \nu_{\mathrm{ij}}\right\rangle$. Also, the performance rating of each alternative versus the objective attributes should be convertible into an intuitionistic fuzzy number. Thus, they can be normalized into the range of $[0,1]$ The normalized performance rating values can be computed as follows:

For benefit attributes, we have:

$\hat{x}_{i j}=x_{i j}-\frac{\min _{j}\left\{x_{i j}\right\}}{\max _{j}\left\{x_{i j}\right\}-\min _{j}\left\{x_{i j}\right\} \backslash-t,}$

and for cost attributes, we have:

$\hat{x}_{i j}=\frac{\max _{j}\left\{x_{i j}\right\}-x_{i j}}{\max _{j}\left\{x_{i j}\right\}-\min _{j}\left\{x_{i j}\right\} \backslash-t .}$

Then, $\hat{x}_{i j}$ can be denoted as an intuitionistic fuzzy number $\tilde{x}_{i j}=\left\langle\mu_{i j}, \nu_{i j}\right\rangle=\left\langle\hat{x}_{i j}, 1-\hat{x}_{i j}\right\rangle$.

An intuitionistic fuzzy decision-making problem under multiple attributes can be concisely provided in matrix format as follows:

$\tilde{R}=\left(\tilde{r}_{i j}\right)_{m \times n}=\left[\begin{array}{llll}\tilde{r}_{11} & \tilde{r}_{12} & \cdots & \tilde{r}_{1 n} \\ \tilde{r}_{21} & \tilde{r}_{22} & \cdots & \tilde{r}_{2 n} \\ \vdots & \vdots & \ddots & \vdots \\ \tilde{r}_{m 1} & \tilde{r}_{m 2} & \cdots & \tilde{r}_{m n}\end{array}\right]$

Step 2. Entropy weights of the attributes are obtained.

$I_{j}$ is computed by (Ye, 2010):

$I_{j}=\frac{1}{m} \sum_{i=1}^{m}\left\{\cos \frac{\pi\left[1+\mu_{i j}-\nu_{i j}\right]}{4}+\cos \frac{\pi\left[1-\mu_{i j}+\nu_{i j}\right]}{4}-1\right\} \times \frac{1}{\sqrt{2}-1}$

where $0 \leq I_{j} \leq 1$, and $j=1,2, \ldots, n$. Then, the entropy weight of the $j$ th attribute can be defined as follows:

$\omega_{j}=\frac{1-I_{j}}{n-\sum_{j=1}^{n} I_{j}}$

where $\omega_{j} \in[0,1]$, and $\sum_{j=1}^{n} \omega_{j}=1$.

Step 3. Final intuitionistic fuzzy weights are determined.

Since the attributes may be different in nature, they can have the different importance. Intuitionistic fuzzy weights of selected attributes can be linguistic variables $\tilde{c}_{j}$ provided by a DM or expert, which can be expressed in intuitionistic fuzzy numbers. Thus, we have:

$\tilde{w}_{j}=\left\langle\mu_{w_{j}}, \nu_{w_{j}}\right\rangle=\alpha \omega_{j} \times(1-\alpha) \tilde{c}_{j}$

where $\tilde{c}_{j}$ is obtained by a DM and $\omega_{j}$ is given by the entropy, $\alpha \in[0,1]$.

Step 4. Intuitionistic fuzzy positive-ideal solution (IF-PIS) and negative-ideal solution (IF-NIS) as $\tilde{r}_{j}^{+}$and $\tilde{r}_{j}^{-}$are determined by:

$\tilde{r}_{j}^{+}=\left\langle\mu_{r_{j}^{+}}(x), \nu_{r_{j}^{+}}(x)\right\rangle$ 


$$
\begin{aligned}
= & \left\langle\left(\left(\max _{i}\left(\mu_{i j}(x)\right) \mid j \in J_{1}\right),\left(\min _{i}\left(\mu_{i j}(x)\right) \mid j \in J_{2}\right)\right),\right. \\
& \left.\left(\left(\min _{i}\left(\nu_{i j}(x)\right) \mid j \in J_{1}\right),\left(\max _{i}\left(\nu_{i j}(x)\right) \mid j \in J_{2}\right)\right)\right\rangle \\
\tilde{r}_{j}^{-}= & \left\langle\mu_{r_{j}^{-}}(x), \nu_{r_{j}^{-}}(x)\right\rangle=\left\langle\left(\left(\min _{i}\left(\mu_{i j}(x)\right) \mid j \in J_{1}\right),\right.\right. \\
& \left.\left(\max _{i}\left(\mu_{i j}(x)\right) \mid j \in J_{2}\right)\right),\left(\left(\max _{i}\left(\nu_{i j}(x)\right) \mid j \in J_{1}\right),\right. \\
& \left.\left.\left(\min _{i}\left(\nu_{i j}(x)\right) \mid j \in J_{2}\right)\right)\right\rangle
\end{aligned}
$$

Let $J_{1}$ and $J_{2}$ be benefit attribute and cost attribute, respectively.

Step 5. Positive-ideal separation matrix $\Delta^{+}$and negative-ideal separation matrix $\Delta^{-}$are constructed according to definition 2.1.6.

$\Delta^{+}=\left[\Delta_{i j}^{+}\right]=\left[\begin{array}{llll}\Delta\left(\tilde{r}_{11}, \tilde{r}_{1}^{+}\right) & \Delta\left(\tilde{r}_{12}, \tilde{r}_{2}^{+}\right) & \cdots & \Delta\left(\tilde{r}_{1 n}, \tilde{r}_{n}^{+}\right) \\ \Delta\left(\tilde{r}_{21}, \tilde{r}_{1}^{+}\right) & \Delta\left(\tilde{r}_{22}, \tilde{r}_{2}^{+}\right) & \cdots & \Delta\left(\tilde{r}_{2 n}, \tilde{r}_{n}^{+}\right) \\ \vdots & \vdots & \ddots & \vdots \\ \Delta\left(\tilde{r}_{m 1}, \tilde{r}_{1}^{+}\right) & \Delta\left(\tilde{r}_{m 2}, \tilde{r}_{2}^{+}\right) & \cdots & \Delta\left(\tilde{r}_{m n}, \tilde{r}_{n}^{+}\right)\end{array}\right]$

and

$$
\Delta^{-}=\left[\Delta_{i j}^{-}\right]=\left[\begin{array}{llll}
\Delta\left(\tilde{r}_{11}, \tilde{r}_{1}^{-}\right) & \Delta\left(\tilde{r}_{22}, \tilde{r}_{2}^{-}\right) & \cdots & \Delta\left(\tilde{r}_{1 n}, \tilde{r}_{n}^{-}\right) \\
\Delta\left(\tilde{r}_{21}, \tilde{r}_{1}^{-}\right) & \Delta\left(\tilde{r}_{22}, \tilde{r}_{2}^{-}\right) & \cdots & \Delta\left(\tilde{r}_{2 n}, \tilde{r}_{n}^{-}\right) \\
\vdots & \vdots & \ddots & \vdots \\
\Delta\left(\tilde{r}_{m 1}, \tilde{r}_{1}^{-}\right) & \Delta\left(\tilde{r}_{m 2}, \tilde{r}_{2}^{-}\right) & \cdots & \Delta\left(\tilde{r}_{m n}, \tilde{r}_{n}^{-}\right)
\end{array}\right] .
$$

Step 6. Grey relational coefficients of each alternative $\left(\xi_{i j}^{+}\right.$and $\xi_{i j}^{-}$) are computed from the IF-PIS and IF-NIS, respectively.

$$
\begin{aligned}
\xi_{i j}^{+} & =\frac{\min _{1 \leq i \leq m 1 \leq j \leq n} \min _{1 \leq j} \Delta_{i j}^{+}+\gamma \max _{1 \leq i \leq m 1 \leq j \leq n} \max _{1 j} \Delta_{i j}^{+}}{\Delta_{i j}^{+}+\gamma \max _{1 \leq i \leq m 1 \leq j \leq n} \max _{i j}^{+}}, i \\
& =1,2, \ldots, m, \quad j \in 1,2, \ldots, n .
\end{aligned}
$$

and

$$
\begin{aligned}
\xi_{i j}^{-} & =\frac{\min _{1 \leq i \leq m 1 \leq j \leq n} \min _{i j} \Delta_{i j}^{-}+\gamma \max _{1 \leq i \leq m 1 \leq j \leq n} \max _{1 j} \Delta_{i j}^{-}}{\Delta_{i j}^{-}+\gamma \max _{1 \leq i \leq m 1 \leq j \leq n} \max _{i j}}, i \\
& =1,2, \ldots, m, \quad j \in 1,2, \ldots, n,
\end{aligned}
$$

where the distinguished coefficient $\gamma$ can be set to 0.5. Eqs. (11) and (12) are presented to assess different relationships among each potential scenario and positive-ideal and negative-ideal solutions under multiple conflicting attributes by grey relations. Step 7. $\Gamma_{i}, \Psi_{i}, \Gamma_{i}^{\prime}$ and $\Psi_{i}^{\prime}$ values are computed for $i=1,2, \ldots, m$ based on the score function in definition 2.1.7 as follows:

$$
\begin{aligned}
\Gamma_{i}= & S\left(\sum_{j=1}^{n} \tilde{w}_{j} \times \frac{\xi_{i j}^{+}}{\left(\xi_{i j}^{+}+\xi_{i j}^{-}\right) \sum_{j=1}^{n}\left(\frac{\xi_{i j}^{+}}{\xi_{i j}^{+}+\xi_{i j}^{-}}\right)}\right) \\
= & 1-\prod_{j=1}^{n}\left(1-\mu_{w_{j}}\right)^{\left.\left(\xi_{i j}^{+} / \xi_{i j}^{+}+\xi_{i j}^{-}\right) \sum_{j=1}^{n}\left(\xi_{i j}^{+} / \xi_{i j}^{+}+\xi_{i j}^{-}\right)\right)} \\
& -\prod_{j=1}^{n}\left(\nu_{w_{j}}\right)^{\left(\xi_{i j}^{+} /\left(\xi_{i j}^{+}+\xi_{i j}^{-}\right) \sum_{j=1}^{n}\left(\xi_{i j}^{+} / \xi_{i j}^{+}+\xi_{i j}^{-}\right)\right)}, \\
\Psi_{i}= & \max _{j} S\left(\tilde{w}_{j} \times \frac{\xi_{i j}^{+}}{\left(\xi_{i j}^{+}+\xi_{i j}^{-}\right) \sum_{j=1}^{n}\left(\frac{\xi_{i j}^{+}}{\xi_{i j}^{+}+\xi_{i j}^{-}}\right)}\right) \\
= & \max _{j}\left(1-\left(1-\mu_{w_{j}}{ }^{\left.\left(\xi_{i j}^{+} /\left(\xi_{i j}^{+}+\xi_{i j}^{-}\right) \sum_{j=1}^{n}\left(\xi_{i j}^{+}\right) \xi_{i j}^{+}+\xi_{i j}^{-}\right)\right)}\right.\right.
\end{aligned}
$$

$$
\begin{aligned}
& \left.-\left(\nu_{w_{j}}\right)^{\left(\xi_{i j}^{+} /\left(\xi_{i j}^{+}+\xi_{i j}^{-}\right) \sum_{j=1}^{n}\left(\xi_{i j}^{+} / \xi_{i j}^{+}+\xi_{i j}^{-}\right)\right)}\right), \\
\Gamma_{i}^{\prime}= & S\left(\sum_{j=1}^{n} \tilde{w}_{j} \times \frac{\xi_{i j}^{-}}{\left(\xi_{i j}^{+}+\xi_{i j}^{-}\right) \sum_{j=1}^{n}\left(\frac{\xi_{i j}^{+}}{\xi_{i j}^{+}+\xi_{i j}^{-}}\right)}\right) \\
= & 1-\prod_{j=1}^{n}\left(1-\mu_{w_{j}}\right)^{\left(\xi_{\bar{j}}^{-} /\left(\xi_{i j}^{+}+\xi_{i j}^{-}\right) \sum_{j=1}^{n}\left(\xi_{i j}^{+} / \xi_{i j}^{+}+\xi_{i j}^{-}\right)\right)} \\
& -\prod_{j=1}^{n}\left(\nu_{w_{j}}\right)^{\left(\xi_{i j}^{-} /\left(\xi_{i j}^{+}+\xi_{i j}^{-}\right) \sum_{j=1}^{n}\left(\xi_{i j}^{+} / \xi_{i j}^{+}+\xi_{i j}^{-}\right)\right)},
\end{aligned}
$$

and

$$
\begin{aligned}
\Psi_{i}^{\prime} & =\max _{j} S\left(\tilde{w}_{j} \times \frac{\xi_{i j}^{-}}{\left(\xi_{i j}^{+}+\xi_{i j}^{-}\right) \sum_{j=1}^{n}\left(\frac{\xi_{i j}^{+}}{\xi_{i j}^{+}+\xi_{i j}^{-}}\right)}\right) \\
= & \max _{j}\left(1-\left(1-\mu_{w_{j}}\right)^{\left(\xi_{\bar{j}}^{-} /\left(\xi_{i j}^{+}+\xi_{i j}^{-}\right) \sum_{j=1}^{n}\left(\xi_{i j}^{+} / \xi_{i j}^{+}+\xi_{i j}^{-}\right)\right)}\right. \\
& \left.-\left(\nu_{w_{j}}\right)^{\left(\xi_{i j}^{-} /\left(\xi_{i j}^{+}+\xi_{i j}^{-}\right) \sum_{j=1}^{n}\left(\xi_{i j}^{+} / \xi_{i j}^{+}+\xi_{i j}^{-}\right)\right)}\right) .
\end{aligned}
$$

where $\Gamma_{i}$ and $\Gamma_{i}^{\prime}$ are regarded to formulate the ranking measure of group utility for each DM; also, $\Psi_{i}$ and $\Psi_{i}^{\prime}$ are taken into account to formulate the individual regret for each DM.

Step 8. Values of indices $\vartheta_{i}$ and $\chi_{i}$ are computed by the following relations:

$\vartheta_{i}=\left(\frac{\Gamma_{i}+\Psi_{i}}{2}\right)\left(\frac{\Gamma_{i}-\Gamma^{+}}{\Gamma^{-}-\Gamma^{+}}\right)+\left(\frac{2-\left(\Gamma_{i}+\Psi_{i}\right)}{2}\right)\left(\frac{\Psi_{i}-\Psi^{+}}{\Psi^{-}-\Psi^{+}}\right)$

and

$\chi_{i}=\left(\frac{\Gamma_{i}^{\prime}+\Psi^{\prime}}{2}\right)\left(\frac{\Gamma_{i}^{\prime}-\Gamma^{\prime-}}{\Gamma^{\prime+}-\Gamma^{\prime-}}\right)+\left(\frac{2-\left(\Gamma_{i}^{\prime}+\Psi^{\prime}\right)}{2}\right)\left(\frac{\Psi_{i}^{\prime}-\Psi^{\prime-}}{\Psi^{\prime+}-\Psi^{\prime-}}\right)$

where

$$
\begin{aligned}
& \left\{\begin{array}{l}
\Gamma^{+}=\min _{i} \Gamma_{i} \\
\Gamma^{-}=\max _{i} \Gamma_{i}
\end{array}, \quad\left\{\begin{array}{l}
\Psi^{+}=\min _{i} \Psi_{i} \\
\Psi^{-}=\max _{i} \Psi_{i}
\end{array}, \quad\left\{\begin{array}{l}
\Gamma^{++}=\max _{i} \Gamma_{i}^{\prime} \\
\Gamma^{\prime-}=\min _{i} \Gamma_{i}^{\prime}, \quad \text { and }
\end{array}\right.\right.\right. \\
& \left\{\begin{array}{l}
\Psi^{\prime+}=\max _{i} \Psi_{i}^{\prime} \\
\Psi^{\prime-}=\min _{i} \Psi_{i}^{\prime}
\end{array}\right.
\end{aligned}
$$

$\left(\frac{\Gamma_{i}+\Psi_{i}}{2}\right)$ and $\left(\frac{\Gamma_{i}^{\prime}+\Psi^{\prime}}{2}\right)$ are regarded as the relative importance for the strategy of the majority attributes, whereas $\left(\frac{2-\left(\Gamma_{i}+\Psi_{i}\right)}{2}\right)$ and $\left(\frac{2-\left(\Gamma_{i}^{\prime}+\Psi^{\prime}\right)}{2}\right)$ are the relative importance of the individual regret. The values are provided by DMs through the group decisionmaking process. In common practice, we can set these values equal to 0.5 (e.g., Vahdani et al., 2013a). In fact for the compromise solution approaches, when the values of $\left(\frac{\Gamma_{i}+\Psi_{i}}{2}\right)$ and $\left(\frac{\Gamma_{i}^{\prime}+\Psi^{\prime}}{2}\right)$ can be set to “ $\approx 1$ ", it denotes a group decisionmaking process that could employ the strategy of maximum group utility; whereas the values are set to " $\approx 0$ ", it denotes a group decision-making process that could employ the strategy of minimum individual regret, which is presented among maximum individual regrets.

Step 9. Ranking index $(R I)$ is calculated by:

$R I_{i}=\vartheta_{i}+\frac{1}{\chi_{i(B)}}+\varepsilon_{i^{\prime}}$,

where the second term refers to all $i$ for which $\chi_{i}>0$ while $\varepsilon_{i^{\prime}}$ refers to all $i^{\prime}$ for which $\chi_{i}=0$ and $\varepsilon_{i^{\prime}}=\left(\min \chi_{i(B)_{i}}\right)^{\min _{j} w_{j}}$, where $\min _{j} w_{j}=\min _{j}\left(\mu_{w_{j}}-\nu_{w_{j}}\right)$.

Step 10 . The alternatives are ranked by considering the RI. The most suitable alternative can be provided by the preference rank order according to $\vartheta_{i}$ and $\chi_{i}$ concurrently. The minimum 
value of the RI indicates the better performance for the alternative $i$.

In sum, the main functions of proposed intuitionistic fuzzy grey distance-based model are the following:

- Creating system evaluation attributes related to system capabilities by considering objectives (Eqs. (1) to (3));

- Extending candidate systems for attaining objectives and weights (Eqs. (4) to (6));

- Apprising alternatives regarding to attributes (values of functions for the attributes; Eqs. (7) to (10));

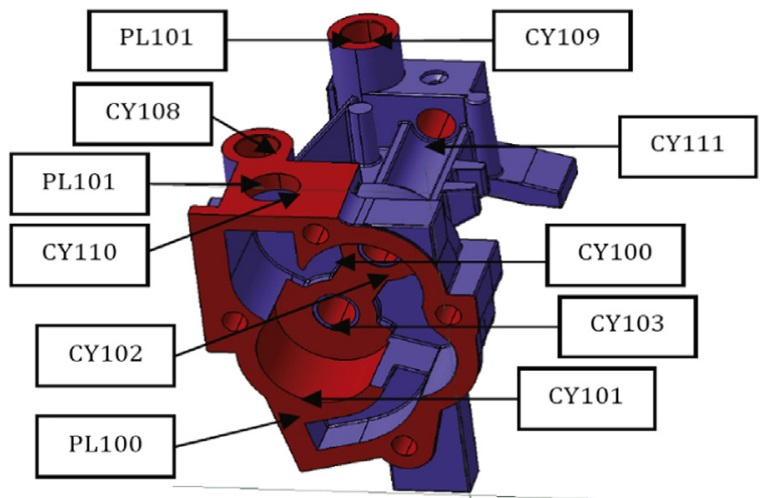

Fig. 1. Oil pump housing (studied part).

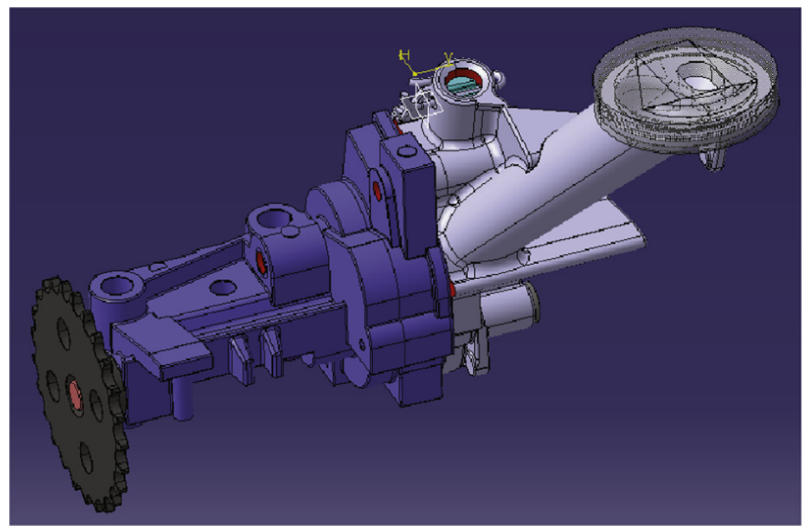

Fig. 2. Oil pump.
- Employing a fuzzy grey multi-attribute analysis method (Eqs. (11) to (18));

- Accepting one candidate as preferred (Eq. (19));

\section{Case study for the inspection planning in automotive industry}

In this section, a real case study is presented for the inspection planning in automotive industry in France. Different scenarios of inspection plans are proposed for the oil pump housing from Renault automobile manufacturing. "Inspection process generation" anticipates to better compromise between the effectiveness of inspection plan and associated cost. In industrial practice, this activity is positioned following the detailed product and manufacturing process design stages. Product descriptions, process and manufacturing capabilities are regarded as entries of this activity. To ease the application of the intuitionistic fuzzy grey distancebased model, a single automotive part of the overall oil pump is studied as depicted in Figs. 1 and 2; the detailed information is also reported in Table 1.

These latter have two roles. They are either the constraints or local performance indicators, encouraging certain decisionmaking choices. Note that the final objective is to propose an effective inspection plan. To be able to judge the effectiveness, the decision making attributes (criteria) should be defined and explained in detail. They are sometimes the extension of local performance indicators to the whole system. Next sub-section details the definition of these attributes.

\subsection{Attributes definition}

In the context, a performance analysis reveals the multiplicity of attributes. These attributes are usually including multiple natures regarding the available knowledge. This determines and constrains the attributes evaluation method for multiple performance facets. This is the decision-making process based on relevant attributes. For an effective decision-making process, it is essential to define and elaborate a decomposition of attributes and sub-attributes. Notably, the attributes can overlap. It means that the sub-attributes can be common to two or more global attributes. It is important to fix the appropriate decomposition of attributes to the context. The definition of a global performance indicator permits to find the best compromise by considering the attributes for an inspection plan solution (i.e., scenario). With a

Table 1

Detailed information for the Oil pump housing.

\begin{tabular}{|c|c|c|c|c|c|}
\hline \multirow[t]{2}{*}{ Operation's designation } & \multicolumn{2}{|c|}{ Operation Capability } & \multirow[t]{2}{*}{ Process station time (min) } & \multicolumn{2}{|c|}{ Non-conformity rate } \\
\hline & $C_{\mathrm{p}}$ & $C_{\mathrm{pk}}$ & & With monitoring & Without monitoring \\
\hline Face milling PL100, rough & 2 & 1.5 & 0.148 & $0 \mathrm{ppm}$ & 7 ppm \\
\hline Face milling PL101, rough & 2 & 1.5 & 0.166 & $0 \mathrm{ppm}$ & 7 ppm \\
\hline Contouring CY110, finish & 2 & 1.66 & 0.133 & $0 \mathrm{ppm}$ & $1 \mathrm{ppm}$ \\
\hline Contouring CY108 and CY 109, rough & 1.6 & 1.33 & 0.154 & $2 \mathrm{ppm}$ & $66 \mathrm{ppm}$ \\
\hline Chamfering CY108 and CY109 at $45^{\circ}$ & 2 & 1.66 & 0.090 & $0 \mathrm{ppm}$ & $1 \mathrm{ppm}$ \\
\hline Chamfering CY100 and CY101 at $45^{\circ}$ & 2 & 1.66 & 0.251 & $0 \mathrm{ppm}$ & $1 \mathrm{ppm}$ \\
\hline Boring CY100, finish & 1.5 & 1.2 & 0.257 & $7 \mathrm{ppm}$ & 318 ppm \\
\hline Boring CY101, finish & 1.5 & 1.2 & 0.257 & $7 \mathrm{ppm}$ & $318 \mathrm{ppm}$ \\
\hline Contouring CY102 and CY 103, rough & 1.66 & 1.3 & 0.122 & $1 \mathrm{ppm}$ & $96 \mathrm{ppm}$ \\
\hline Contouring CY111, rough & 1.66 & 1.4 & 0.109 & $1 \mathrm{ppm}$ & $27 \mathrm{ppm}$ \\
\hline Contouring CY108 and CY 109, finish & 1.66 & 1.4 & 0.134 & $1 \mathrm{ppm}$ & $27 \mathrm{ppm}$ \\
\hline Contouring CY102 and CY103, finish & 1.3 & 1.1 & 0.122 & $96 \mathrm{ppm}$ & $967 \mathrm{ppm}$ \\
\hline Contouring CY111, finish & 1.3 & 1 & 0.122 & 96 ppm & $2700 \mathrm{ppm}$ \\
\hline Face milling PL100, finish & 1.66 & 1.33 & 0.117 & $1 \mathrm{ppm}$ & $66 \mathrm{ppm}$ \\
\hline Face milling PL101, finish & 1.66 & 1.33 & 0.129 & $1 \mathrm{ppm}$ & $66 \mathrm{ppm}$ \\
\hline
\end{tabular}


generic view on the product, manufacturing process and resources, inspection plan and resources, three global attributes are identified based on experiences of the professional experts, namely cost, difficulty realization and customer satisfaction, to cover all performance facets as provided in Fig. 3.

\subsubsection{Cost attribute}

An analytical approach is employed to evaluate the cost of a solution, translated to the cost of quality provided by each scenario. There are direct or indirect costs and deviations. The evaluations can be focused on particular activities in the manufacturing and inspection as follows:

- Manufacturing (milling, forging, casting)

- Process monitoring (detective/corrective)

- Product control (sampling rate/total inspection)

One of the assumptions of this work is that there is no rework following failure detection, maintenance and assembly activities. Therefore, the inspection activities are regarded as on-line activities. For these activities, enough information is usually available to estimate the cost attribute affected directly.

Apart from these direct costs, two other important expense sources which increase the final cost, are the emergence of internal and external failures. They cause two non-productive sources of cost, including product scraping (recycling) and product maintenance, customer loss and customer claim. Product scraping or internal failure cost is also taken into account in the cost evaluation as it could be simply estimated. From an industrial point of view, the scraping cost is twice as high as manufacturing cost in long term. However, the difficulty of estimating external failure cost leads us to believe that it would be better to evaluate the non-conformity rate, seen by the customer, in a subjective way as a sub-attribute for customer satisfaction instead of cost. The cost would break down to product maintenance, customer loss, customer claim costs depending on competitive economic context. They may be further classified into overt and hidden external failure costs (Galin, 2004).

\subsubsection{Difficulty realization attribute}

This attribute is generally translated through the capability. The capability is a measurable performance indicator to quantify the process ability with respect to the tolerances set by the specifications, and allows an objective choice of the quality level. Capability indicators are designed to represent the performance of the production, regarding the pre-defined objective. Also, the attribute can be synonymous with the production failure frequency and failure detection and prevention difficulty. To evaluate this attribute for the set of decision leading to a solution, the following subattributes should be considered:

- The sub-attribute capability representative of all operations as a whole; to do so it is recommended to take the minimum operation capabilities' values into account as the worst case performance of the process.

- The sub-attribute scrap representative of non-conformity rate either observed by customer or detected by inspection for each scenario.

- The sub-attribute failure detection and prevention time, the estimation of whole inspection time as the failure detection or prevention difficulty; the planning of inspection activities will impact on this sub-attribute, related to production system failure detection or maladjustment.

The estimation of realization difficulty cannot be as precise as the cost estimation. It is pointed out that the available information is based on statistical data as the estimation of capability and the scrap rate given the inspection risk. To provide the performance rating of each scenario versus the attribute, linguistic variables can be properly utilized and converted into intuitionistic fuzzy numbers.

\subsubsection{Customer satisfaction attribute}

This attribute can take several forms: severity of each product or part characteristics and the process parameters from the designer's viewpoint to ensure the functionality of product, and the importance for characteristics from customer's viewpoint. However, these two forms are not necessarily identical. Also, regarding the design stage in which the case study is taking place, we do not possess the customers' feedback on the consequence of neither product design nor manufacturing process and inspection plan. This could not be feasible during the conception stages before releasing the product due to the lack of information. This is why the customer satisfaction is regarded as a subjective measure depending on how customer perceives the product and its usage.

For each alternative of solution, an objective estimation of external non-conformity rate, observed by customer, from manufacturer's viewpoint leads to a subjective estimation of the customer

\begin{tabular}{|l|}
\hline \multicolumn{1}{|c|}{ Cost } \\
\hline - Manufacturing \\
- $\quad$ Time \\
- Control of time unit \\
- Time \\
- $\quad$ Cost of time unit \\
- $\quad$ Control non-detection risk \\
Monitoring \\
- Time \\
- $\quad$ Cost of time unit \\
Scrap \\
- $\quad$ Cost of time unit \\
$\quad$ Control false alarm risk \\
$\quad$ Non-conformity rate \\
Control false alarm risk
\end{tabular}

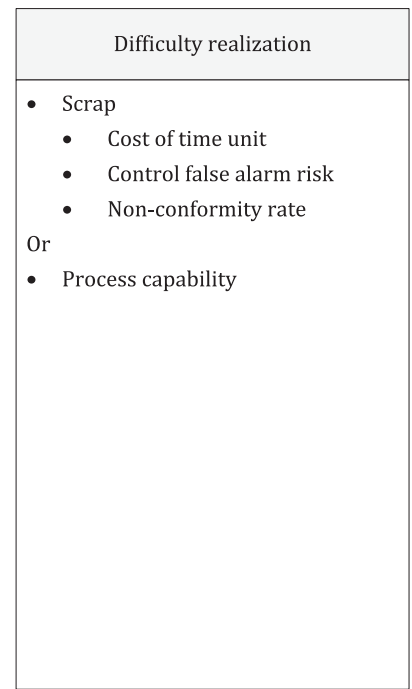

Fig. 3. Attributes' decomposition.

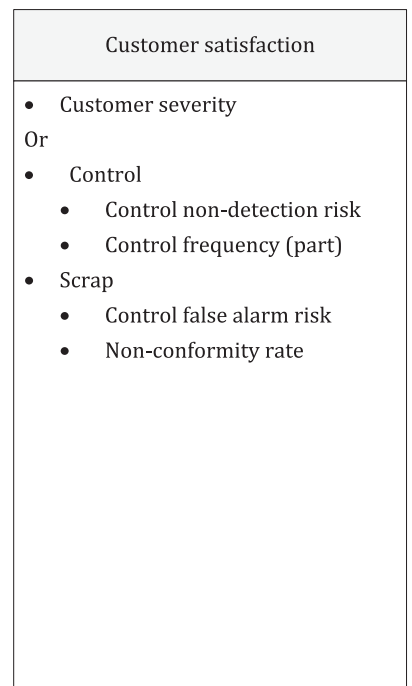


satisfaction. A quotation scale should be defined to assess the risk of non-conformity for the customer or user regarding to estimated external non-conformity rate. The adaptation of the attribute's definition for the available information conducts to evaluate this latter based on the risk of non-detection for the non-conformity of characteristics via the selected inspection means. It is usually interpreted as the difficulty of detection. The non-conformity rate, observed by customers, is affected by the measurement uncertainty and frequency. It naturally depends on the capability of the process and the real non-conformity rate underlying the observed and detected failures. The sub-attribute is defined as the ratio between the number of defective products and the total number of delivered products.

It can be seen that the MADM models is essential for the generation of an inspection plan. At the same time these attributes take different forms through a multi-level context. Causal relationship between product or part characteristics and manufacturing process parameters and resources motivates an inspection plan comprising product conformity control and process monitoring. In fact, at product level the main attribute is regarded as the customer satisfaction. It often triggers the conformity control activities to verify the product or part specifications to ensure the expected functionality. Also, at process level that ensures the specifications, capability of manufacturing operations and rate of defective products are deduced from a global attribute as the difficulty of realization. This attribute triggers not only the manufacturing process monitoring but also the conformity control. The goal is to detect the problems during the production or prevention of these latter by the monitoring. Finally, at inspection control and monitoring level particularly for resource selection, the capability of inspection means, their efficiency, given the risks (i.e., inspection uncertainty) and inspection cost, have a strong impact on the generation of inspection process at the selection of control and monitoring modes and frequencies. To accomplish the coconception of product control and process monitoring, it is necessary to exploit the links among product requirements, part characteristics to control, and the process parameters to monitor.

This paper aims to consider the inspection tasks at different above-mentioned levels by introducing a new intuitionistic fuzzy grey distance-based model. To employ the proposed fuzzy grey decision model, the inspection plan scenarios are described in the next sub-section where those three main attributes are regarded as the global attribute or criteria for the evaluation and selection problem.

\subsection{Implementation}

There are different factors to be considered in the case study for solving the inspection scenario selection problem. The identification of each scenario and the best selection among them can improve the firm's performance in the tactical and operational point of views. For this purpose, five inspection scenarios are presented as follows:

- Scenario 1: Product conformity control at the end of process

- Scenario 2: Process monitoring for all operations with $C_{p}<1.6$

- Scenario 3: Product control conformity at the end of process, and the process monitoring for all operations $C_{p}<1.6$

- Scenario 4: Product conformity control at the end of all operations with $C_{p k}<1.4$

- Scenario 5: Product conformity control at the end of all operations $C_{p}$ (monitoring) $<1.4$, and the process monitoring for all operations $C_{p}<1.6$

It is pointed out that the main characteristics of this scenario planning are described in detail in sub-section 4.1. Consequently, these scenarios are evaluated versus the cost $(€)$, difficulty realization and customer satisfaction (part per million (ppm)) as three evaluation attributes. The best scenario is selected on the basis of these main evaluation attributes by the proposed fuzzy grey distance-based model. Indeed, these scenarios propose an inspection plan including product conformity control and/or process monitoring activities. Conformity controls are taken place with $100 \%$ frequency, and process monitoring is applied by regarding a unit of the time on manufacturing resources, provided their station time. Also, the relative importance of the selected attributes is obtained by using the following linguistic variables: very unimportant (VUI), unimportant (UI), medium (M), important (I) and very important (VI), defined in Table 4.

The performance ratings of the inspection scenarios in terms of the attributes are characterized by the following linguistic terms: very low $(\mathrm{VL})$, low $(\mathrm{L})$, medium $(\mathrm{M})$, medium $(\mathrm{M})$, high $(\mathrm{H})$, very high $(\mathrm{VH})$, which are defined in Tables 2 and 3.

Three main attributes (i.e., cost, difficulty realization and customer satisfaction) are identified for the scenario selection problem of inspection planning, which are denoted as $M A_{1}, M A_{2}$, and $M A_{3}$. Also, five potential scenarios or candidates are provided for the evaluation process of the most suitable one, which are denoted as $S_{1}, S_{2}, S_{3}, S_{4}$ and $S_{5}$. The intuitionistic fuzzy ratings of the five scenarios for the inspection planning as candidates by the linguistic variables and their respective numbers in Tables 2 and 3 are evaluated by the experts with respect to each subjective attribute. Also, the numerical values for each scenario versus objective attribute (i.e., cost attribute) are obtained as reported in Table 5 (step 1 ).

Entropy weights of three main attributes are obtained by using Eqs. (4) and (5) (step 2). The relative importance (weight) of each selected attributes by professional experts is subjectively described by linguistic terms and is transformed into intuitionistic fuzzy numbers. Thus, the weights of the main attributes subjectively provided by the professional experts are important (I), medium (M), and very important (VI), respectively. Consequently, the final weight of each selected attributes by using the proposed weighting method (Eq. (6)) is reported in Table 6 (Step 3).

The intuitionistic fuzzy performance matrix is formed as illustrated in Table 7, including the IF-PIS and IF-NIS by Eqs. (7) and (8) (step 4). Then, positive-ideal separation matrix $\Delta^{+}$

Table 2

5-scale for the difficulty realization attribute by linguistic variables.

\begin{tabular}{llll}
\hline Capability & $\begin{array}{l}\text { Non- } \\
\text { conformity rate }\end{array}$ & $\begin{array}{l}\text { Linguistic } \\
\text { variables }\end{array}$ & $\begin{array}{l}\text { Intuitionistic } \\
\text { fuzzy numbers }\end{array}$ \\
\hline$>1.6$ & $\begin{array}{l}0.0005 \\
0.0020>>\end{array}$ & $\begin{array}{l}\text { Very high }(\mathrm{VH}) \\
\text { High }(\mathrm{H})\end{array}$ & $\begin{array}{l}(0.90,0.10,0.00) \\
(0.75,0.20,0.05)\end{array}$ \\
$1.4<<1.6$ & $\begin{array}{l}0.0005 \\
1.0035>>\end{array}$ & Medium $(\mathrm{M})$ & $(0.50,0.45,0.05)$ \\
$1<<1.4$ & $\begin{array}{l}0.0020 \\
0.0050>\end{array}$ & Low $(\mathrm{L})$ & $(0.35,0.60,0.05)$ \\
& $>0.0035$ & Very low $(\mathrm{VL})$ & $(0.10,0.90,0.00)$ \\
\hline
\end{tabular}

Table 3

5-scale for the customer satisfaction attribute.

\begin{tabular}{lll}
\hline $\begin{array}{l}\text { External non-conformity } \\
\text { rate }\end{array}$ & $\begin{array}{l}\text { Linguistic } \\
\text { variables }\end{array}$ & $\begin{array}{l}\text { Iintuitionistic fuzzy } \\
\text { numbers }\end{array}$ \\
\hline$<50$ & Very high $(\mathrm{VH})$ & $(0.90,0.10,0.00)$ \\
$200>>50$ & High $(\mathrm{H})$ & $(0.75,0.20,0.05)$ \\
$350>>200$ & Medium (M) & $(0.50,0.45,0.05)$ \\
$500>>350$ & Low (L) & $(0.35,0.60,0.05)$ \\
$>500$ & Very low (VL) & $(0.10,0.90,0.00)$ \\
\hline
\end{tabular}


and negative-ideal separation matrix $\Delta^{-}$are constructed as follows (step 5):

$\Delta^{+}=\left[\Delta_{i j}^{+}\right]=\left[\begin{array}{lll}0.873 & 0.676 & 0.278 \\ 1.000 & 0.000 & 0.800 \\ 0.875 & 0.000 & 0.000 \\ 0.000 & 0.800 & 0.278 \\ 0.249 & 0.427 & 0.278\end{array}\right]$

and

$\Delta^{-}=\left[\Delta_{i j}^{-}\right]=\left[\begin{array}{lll}0.127 & 0.132 & 0.527 \\ 0.000 & 0.800 & 0.000 \\ 0.125 & 0.800 & 0.800 \\ 1.000 & 0.000 & 0.527 \\ 0.751 & 0.377 & 0.527\end{array}\right]$.

Grey relational coefficients of each scenario for the inspection planning are computed from the IF-PIS and IF-NIS, using Eqs. (11) and (12), as below (step 6):

$\xi^{+}=\left[\begin{array}{lll}0.364 & 0.425 & 0.642 \\ 0.333 & 1.000 & 0.385 \\ 0.364 & 1.000 & 1.000 \\ 1.000 & 0.385 & 0.642 \\ 0.667 & 0.539 & 0.642\end{array}\right]$

and

$\xi^{-}=\left[\begin{array}{lll}0.797 & 0.791 & 0.487 \\ 1.000 & 0.385 & 1.000 \\ 0.799 & 0.385 & 0.385 \\ 0.333 & 1.000 & 0.487 \\ 0.400 & 0.570 & 0.487\end{array}\right]$

The values of $\Gamma_{i}, \Psi_{i}, \Gamma_{i}^{\prime}$ and $\Psi_{i}^{\prime}$ are computed according to definition 2.1.7 for five scenarios based on their score functions (step 7). Finally, the score of each scenario by the proposed RI function

Table 4

Linguistic variables for the relative importance of main evaluation attributes.

\begin{tabular}{ll}
\hline Linguistic variables & Intuitionistic fuzzy numbers \\
\hline Very important (VI) & $(0.90,0.10,0.00)$ \\
Important (I) & $(0.75,0.20,0.05)$ \\
Medium (M) & $(0.50,0.45,0.05)$ \\
Unimportant (UI) & $(0.35,0.60,0.05)$ \\
Very unimportant (VUI) & $(0.10,0.90,0.00)$ \\
\hline
\end{tabular}

Table 5

Ratings of five scenarios of the inspection planning versus main selected attributes.

\begin{tabular}{llll}
\hline Scenarios of the inspection planning & \multicolumn{2}{l}{ Main attributes } \\
\cline { 2 - 4 } & $M A_{1}$ & $M A_{2}$ & $M A_{3}$ \\
\hline$S_{1}$ & 0.8586 & $\mathrm{H}$ & $\mathrm{L}$ \\
$S_{2}$ & 0.6755 & $\mathrm{VL}$ & $\mathrm{VH}$ \\
$S_{3}$ & 0.8562 & $\mathrm{VL}$ & $\mathrm{VL}$ \\
$S_{4}$ & 2.1160 & $\mathrm{VH}$ & $\mathrm{L}$ \\
$S_{5}$ & 1.7570 & $\mathrm{M}$ & $\mathrm{L}$ \\
\hline
\end{tabular}

(Eq. (19)) is obtained (step 8). For instance, we have for the third scenario $\left(S_{3}\right)$ :

$$
\begin{aligned}
\Gamma_{3}= & 1-\left((1-0.152)^{0.178} \times(1-0.053)^{0.411} \times(1-0.113)^{0.411}\right) \\
& -\left(0.826^{0.178} \times 0.939^{0.411} \times 0.887^{0.411}\right)=-0.800 \\
\Psi_{3}= & \max \left(\left(1-(1-0.152)^{0.178}-0.826^{0.178}\right),\left(1-(1-0.053)^{0.411}\right.\right. \\
& \left.\left.-0.939^{0.411}\right),\left(1-(1-0.113)^{0.411}-0.887^{0.411}\right)\right)=-0.904 \\
\Gamma_{3}^{\prime}= & 1-\left((1-0.152)^{0.553} \times(1-0.053)^{0.224} \times(1-0.113)^{0.224}\right) \\
& -\left(0.826^{0.553} \times 0.939^{0.224} \times 0.887^{0.224}\right)=-0.742
\end{aligned}
$$

$$
\begin{aligned}
\Psi_{3}^{\prime}= & \max \left(\left(1-(1-0.152)^{0.553}-0.826^{0.553}\right)\right. \\
& \left(1-(1-0.053)^{0.224}-0.939^{0.224}\right),\left(1-(1-0.113)^{0.224}\right. \\
& \left.\left.-0.887^{0.224}\right)\right)=-0.813
\end{aligned}
$$

$\vartheta_{3}=0.5 \times\left(\frac{-0.800+0.816}{-0.745+0.816}\right)+0.5 \times\left(\frac{-0.904+0.930}{-0.840+0.930}\right)=0.257$

and

$\chi_{3}=0.5 \times\left(\frac{-0.742+0.812}{-0.742+0.812}\right)+0.5 \times\left(\frac{-0.813+0.927}{-0.813+0.927}\right)=1.000$

Thus, $\quad R I_{3}=\vartheta_{3}+\frac{1}{\chi_{3(B)}}+\varepsilon_{i^{\prime}}=0.257+1.000+0=1.257$, in which $\varepsilon_{i^{\prime}}$ refers to all $i^{\prime}$ for which $\chi_{i}=0$, therefore, we have $\varepsilon_{i^{\prime}}=0$.

Notably that for $R I_{4}$ we have $\chi_{4(B)}=0$; then, the ranking index is $R I_{4}=\vartheta_{4}+\varepsilon_{i^{\prime}}=1.000+2.998=3.998$, where the second term $\frac{1}{\chi_{i(B)}}$ refers to all $i$ for which $\chi_{i}>0$ and it cannot be considered in the formulation of $R I_{4}$ while $\varepsilon_{i^{\prime}}$ refers to all $i^{\prime}$ for which $\chi_{4}=0$ and $\varepsilon_{i^{\prime}}=$ $\left(\min \chi_{i(B)}\right)^{\min _{j} w_{j}}=2.998$, where $\min _{j} w_{j}=\min _{j}\left(\mu_{w_{j}}-\nu_{w_{j}}\right.$ ). The final res ults are reported in Table 8.

According to Table 8, the ranking order of five scenarios for the inspection planning is $S_{3}, S_{2}, S_{1}, S_{4}$ and $S_{5}$ (step 9). The most

\begin{tabular}{|c|c|c|c|}
\hline & $M A_{1}$ & $M A_{2}$ & $M A_{3}$ \\
\hline Intuitionistic fuzzy number & $(0.152,0.826,0.022)$ & $(0.053,0.939,0.008)$ & $(0.113,0.887,0.000)$ \\
\hline
\end{tabular}
desirable selection is scenario $3\left(S_{3}\right)$ after implementing the proposed intuitionistic fuzzy grey decision model.

Table 7

Intuitionistic fuzzy performance matrix of five scenarios versus selected main attributes including the IF-PIS and IF-NIS.

\begin{tabular}{llll}
\hline $\begin{array}{l}\text { Scenarios } \\
\text { of the } \\
\text { inspection } \\
\text { planning }\end{array}$ & $M A_{1}$ & $M a i n$ attributes & \\
\cline { 2 - 4 } & & $M A_{2}$ & $M A_{3}$ \\
\hline$S_{1}$ & $(0.873,0.127,0.000)$ & $(0.750,0.200,0.050)$ & $(0.350,0.600,0.050)$ \\
$S_{2}$ & $(1.000,0.000,0.000)$ & $(0.100,0.900,0.000)$ & $(0.900,0.100,0.000)$ \\
$S_{3}$ & $(0.875,0.125,0.000)$ & $(0.100,0.900,0.000)$ & $(0.100,0.900,0.000)$ \\
$S_{4}$ & $(0.000,1.000,0.000)$ & $(0.900,0.100,0.000)$ & $(0.350,0.600,0.050)$ \\
$S_{5}$ & $(0.249,0.751,0.000)$ & $(0.500,0.450,0.050)$ & $(0.350,0.600,0.050)$ \\
IF-PIS & $(0.000,1.000,0.000)$ & $(0.100,0.900,0.000)$ & $(0.100,0.900,0.000)$ \\
IF-NIS & $(1.000,0.000,0.000)$ & $(0.900,0.100,0.000)$ & $(0.900,0.100,0.000)$ \\
\hline
\end{tabular}




\subsection{Discussion}

In the proposed intuitionistic fuzzy grey decision model, the gap between the ideal solutions and each scenario for the inspection planning is determined along with the ranking order of the scenarios. Also, the sensitive analysis is performed for different values of the distinguished coefficient as influential parameter and consequently the values of the $R I$ for each scenario are reported as illustrated in Fig. 4. The results indicate that the presented model can utilize any distinguished coefficient values to take account of the gap among the RI values of different scenarios, which can assist the top managers in the manufacturing firms to obtain the best scenario in the inspection planning for the selection problem.

Indeed, the proposed decision model employs the key concepts and principles of the IFSs and GRA to deal with the vague information and experts judgments under uncertainty. In fact, the model based on the compromise programming method and idea solutions along with the IFSs and grey theory can determine more flexibility to represent the imprecise/vague information resulting from a lack of data. Furthermore, a weighting method is extended based on the intuitionistic entropy method and experts' opinions as a reasonable way for the main attributes' weights by regarding a new intuitionistic fuzzy grey compromise ratio index for the evaluation, resulting in robust decisions in the manufacturing firms under uncertainty.

A comparative result has been made in Table 9 between the proposed intuitionistic fuzzy grey model and the recent IF-TOPSIS method presented in (Boran et al., 2009). Both decision methods have ranking problematic under uncertainty. The results show that the ranking orders of five scenario planning are the same although the proposed model has main advantages in concepts and functions of the fuzzy and grey approaches compared with recent methods in the literature.

In addition, we have discussed the results of the presented decision model with the professional experts within the common meeting for the inspection planning in the studied company, which have demonstrated that the results provided by the proposed intuitionistic fuzzy grey model are appealing. For instance, the result of rankings, given in Table 8 , shows that the scenario 3 (i.e., $S_{3}$, product control conformity at the end of process, and the process monitoring for all operations $C_{p}<1.6$ ) is the first among potential candidates for the inspection planning in the above-mentioned company. When discussing these rankings of the presented decision model with the experts, they have confirmed that the best candidate $\left(S_{3}\right)$ has been more appropriate than others in the selection problem for the oil pump housing. In fact, these professional experts have approved the results of the intuitionistic fuzzy grey model for the selection problem of the inspection planning in Renault automobile manufacturing.

\section{Concluding remarks}

The scenario evaluation and selection problem in the manufacturing planning is complex because of their different conflicting attributes and features. To make an appropriate decision, several

Table 9

A comparative result between the proposed model and the recent decision method in the literature.

\begin{tabular}{llllll}
\hline $\begin{array}{l}\text { Scenarios of the } \\
\text { inspection planning }\end{array}$ & \multicolumn{2}{l}{ Proposed model } & & \multicolumn{2}{l}{$\begin{array}{l}\text { IF-TOPSIS method by } \\
\text { (Boran et al., 2009) }\end{array}$} \\
\cline { 2 - 3 } \cline { 5 - 6 } & $R I$ & Final ranking & & $C_{i}^{*}$ & Final ranking \\
\hline$S_{1}$ & 2.348 & 3 & 0.551 & 3 \\
$S_{2}$ & 1.276 & 2 & 0.649 & 2 \\
$S_{3}$ & 1.257 & 1 & 0.917 & 1 \\
$S_{4}$ & 3.998 & 4 & 0.341 & 5 \\
$S_{5}$ & 4.123 & 5 & 0.449 & 4 \\
\hline
\end{tabular}

Table 8

Computational results of proposed intuitionistic fuzzy grey decision model.

\begin{tabular}{|c|c|c|c|c|c|c|c|c|}
\hline \multirow[t]{2}{*}{ Scenarios of the inspection planning } & \multirow[t]{2}{*}{$\Gamma_{i}$} & \multirow[t]{2}{*}{$\Psi_{i}$} & \multirow[t]{2}{*}{$\Gamma_{i}^{\prime}$} & \multirow[t]{2}{*}{$\Psi_{i}^{\prime}$} & \multicolumn{2}{|c|}{ Indexes values } & \multirow[t]{2}{*}{ RI } & \multirow[t]{2}{*}{ Final ranking } \\
\hline & & & & & $\vartheta_{i}$ & $\chi_{i(B)}$ & & \\
\hline$S_{1}$ & -0.778 & -0.891 & -0.774 & -0.867 & 0.478 & 0.535 & 2.348 & 3 \\
\hline$S_{2}$ & -0.816 & -0.930 & -0.747 & -0.853 & 0.000 & 0.784 & 1.276 & 2 \\
\hline$S_{3}$ & -0.800 & -0.904 & -0.742 & -0.813 & 0.257 & 1.000 & 1.257 & 1 \\
\hline$S_{4}$ & -0.745 & -0.840 & -0.812 & -0.927 & 1.000 & 0.000 & 3.998 & 4 \\
\hline$S_{5}$ & -0.767 & -0.872 & -0.787 & -0.902 & 0.667 & 0.289 & 4.123 & 5 \\
\hline
\end{tabular}

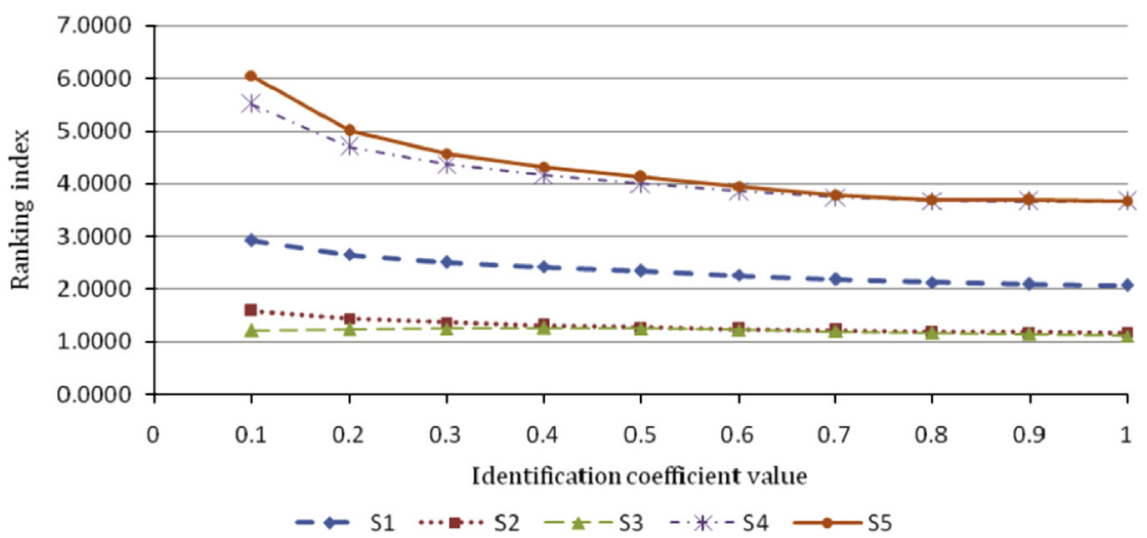

Fig. 4. Variation analysis on the RI values for the different scenarios by each distinguished coefficient value. 
potential scenarios can be presented by regarding individual levels of satisfactions for top and line managers in manufacturing firms. Then, the best scenario should be recognized and then selected among them versus multiple evaluation attributes under uncertainty that appears to be very difficult. This paper has introduced a new distance-based decision model under uncertainty versus multiple criteria in real-life inspection applications. The presented model has been based on main concepts and principles of intuitionistic fuzzy sets theory and grey relational analysis as well as the uncertain compromise programming approach to the scenario evaluation and selection problem in manufacturing firms. Firstly, linguistic variables characterized by intuitionistic fuzzy numbers, considering the truthmembership function and non-truth-membership function, have been regarded to obtain the relative importance of each selected scenario as potential candidate for the inspection planning and to provide their performance ratings versus subjective attributes. Also, numerical values versus the objective attributes have been simultaneously considered. Secondly, a weighting method has been extended according to generalized version of the entropy analysis and intuitionistic fuzzy sets as well as experts' judgments to provide the final weight of main evaluation attributes. Thirdly, a new grey relational analysis, embedded with an intuitionistic fuzzy distance measurement by degrees of the satisfaction and non-satisfaction, has been proposed to appraise the extent of connections between two potential scenarios. Finally, a new compromise ratio index has been presented based on the concepts of intuitionistic fuzzy sets and grey theory as well as ideal solutions, as it can play a significant role in the scenario evaluation and selection problems for the manufacturing planning. In addition, a real case study for the inspection planning in automotive industry has been provided to demonstrate and validate the proposed distance-based model in the manufacturing firm successfully. Different scenarios for the inspection planning have been recognized for the oil pump housing from Renault automobile manufacturing, and then they have been evaluated by the presented model in the real-life situations. Also, the sensitivity analysis has been performed on influential parameter in the evaluation process. The results have demonstrated that the final rankings of inspection scenarios in an uncertain environment have remained stable throughout these changes. For further research, the development of decision support system can be recommended to solve the discrete multi-attributes decision problems in the manufacturing firms via the proposed intuitionistic fuzzy grey model.

\section{Acknowledgments}

This work has been supported by the Center for International Scientific Studies \& Collaboration (CISSC) and the French Embassy in Tehran. The authors gratefully acknowledge this support. We are also grateful for the financial support from the Egide Program in France. Additionally, the authors would like thank anonymous reviewers for their insightful and constructive comments to improve the quality of the manuscript.

\section{References}

Atanassov, K.T., 1986. Intuitionistic fuzzy sets. Fuzzy Sets Syst. 20, 87-96.

Bana e Costa, C.A., Carmen Carnero, M., Duarte Oliveira, M., 2012. A multi-criteria model for auditing a predictive maintenance programme. Eur. J. Oper. Res. 217, $381-393$.

Boran, F.E., Genç, S., Kurt, M., Akay, D., 2009. A multi-criteria intuitionistic fuzzy group decision making for supplier selection with TOPSIS method. Expert. Syst. Appl. 36 (8), 11363-11368.

Chen, M.-F., Tzeng, G.-H., 2004. Combining grey relation and TOPSIS concepts for selecting an expatriate host country. Math. Comput. Model. 40 (13), 1473-1490.

De, S.K., Biswas, R., Roy, A.R., 2000. Some operations on intuitionistic fuzzy sets. Fuzzy Sets Syst. 114, 477-484.

Deng. J., 1982. Control problems of grey systems. Syst. Control. Lett. 5 (2), 288-294.

Deng, J., 1989a. Grey information space. J. Grey Syst. 1 (1), 103-117.

Deng, J., 1989b. Introduction to grey theory system. J. Grey Syst. 1 (1), 1-24.

Deng, J.L., 1988. Properties of relational space for grey systems. In Essential Topics on Grey System - Theory and Applications. Ocean, Beijing China, pp. 1-13.

Ebrahimnejad, S., Mousavi, S.M., Tavakkoli-Moghaddam, R., Hashemi, H., Vahdani, B., 2012. A novel two-phase group decision-making approach for construction project selection in a fuzzy environment. Appl. Math. Model. 36 (9), 4197-4217.

Ferreira, R.J.P., Teixeirade Almeida, A., Cavalcante, C.A.V., 2009. A multi-criteria decision model to determine inspection intervals of condition monitoring based on delay time analysis. Reliab. Eng. Syst. Saf. 94, 905-912.

Galin, D., 2004. Toward an inclusive model for the costs of software quality. Softw. Qual. Prof. 6 (4), 25-31.

Hamzacebi, C., Pekkaya, M., 2011. Determining of stock investments with grey relational analysis. Expert. Syst. Appl. 38, 9186-9195.

Jiang, Y., Tang, Y., Chen, Q., 2011. An adjustable approach to intuitionistic fuzzy soft sets based decision making. Appl. Math. Model. 35 (2), 824-836.

Mojtahedi, S.M.H., Mousavi, S.M., Makui, A., 2010. Project risk identification and assessment simultaneously using multi-attribute group decision making technique. Saf. Sci. 48 (4), 499-507.

Mousavi, S.M., Jolai, F., Tavakkoli-Moghaddam, R., 2013a. A fuzzy stochastic multiattribute group decision-making approach for selection problems. Group Decis. Negotiat. 22 (2), 207-233.

Mousavi, S.M., Torabi, S.A., Tavakkoli-Moghaddam, R., 2013b. A hierarchical group decision-making approach for new product selection in a fuzzy environment. Arab. J. Sci. Eng. 38 (11), 3233-3248.

Mousavi, S.M., Vahdani, B., Tavakkoli-Moghaddam, R., Ebrahimnejad, S., Amiri, M. 2013c. A multi-stage decision making process for multiple attributes analysis under an interval-valued fuzzy environment. Int. J. Adv. Manuf. Technol. 64, 1263-1273.

Pandey, P.C., Kengpol, A., 1995. Selection of an automated inspection system using multiattribute decision analysis. Int. J. Prod. Econ. 39 (3), 289-298.

Singh, R.K., Benyoucef, L., 2011. A fuzzy TOPSIS based approach for e-sourcing. Eng. Appl. Artif. Intell. 24 (3), 437-448.

Szmidt, E., Kacprzyk, J., 2000. Distances between intuitionistic fuzzy sets. Fuzzy Sets Syst. $114,505-518$

Vahdani, B., Mousavi, S.M., Hashemi, H., Mousakhani, M., Tavakkoli-Moghaddam, R., 2013a. A new compromise solution method for fuzzy group decision-making problems with an application to the contractor selection. Eng. Appl. Artif. Intell. 26, 779-788.

Vahdani, B., Mousavi, S.M., Tavakkoli-Moghaddam, R., 2011. Group decision making based on novel fuzzy modified TOPSIS method. Appl. Math. Model. 35, 4257-4269.

Vahdani, B., Mousavi, S.M., Tavakkoli-Moghaddam, R., Hashemi, H., 2013b. A new design of the elimination and choice translating reality method for multiple criteria group decision-making in an intuitionistic fuzzy environment. Appl. Math. Model. 37, 1781-1799.

Wu, H.-H., 2002. A Comparative study of using grey relational analysis in multiple attribute decision making problems, Qual. Eng. 15 (2), 209-217.

Xu, Z.S., 2007a. A survey of preference relations. Int. J. Gen. Syst. 36, 179-203.

$\mathrm{Xu}, \mathrm{Z}$.S., 2007b. Intuitionistic preference relations and their application in group decision making. Inf. Sci. 177, 2363-2379.

Xu, Z.S., Yager, R.R., 2006. Some geometric aggregation operators based on intuitionistic fuzzy sets. Int. J. Gen. Syst. 35, 417-433.

Ye, J., 2010. Two effective measures of intuitionistic fuzzy entropy. Computing 87 (1-2), 55-62.

Zadeh, L.A., 1965. Fuzzy sets. Inf. Control 8, 338-353.

Zhao, F., Xu, X., Xie, S.Q., 2009. Computer-aided inspection planning-the state of the art. Comput. Ind. 60, 453-466. 